\title{
Modeling chlorine distribution in water supply system utilizing empirically determined chlorine decay rate
}

\author{
Anna Musz-Pomorska ${ }^{1,{ }^{*}, \text { Marcin K. Widomski }{ }^{1}, \text { Agnieszka } \text { Matczuk }^{2} \text {, and Konrad Sadura }}{ }^{2}$ \\ ${ }^{1}$ Faculty of Environmental Engineering, Lublin University of Technology, ul. Nadbystrzycka 40B, \\ 20-618 Lublin, Poland \\ ${ }^{2}$ Graduate of the Lublin University of Technology
}

\begin{abstract}
Analysis of free chlorine propagation in water supply network has a significant meaning for the process of water distribution. Results of numerical studies allow the proper selection of disinfectant or suitable monitoring of pipelines endangered by stagnation of water. The first-order reaction of chlorine decay in pipe boundary layer and inside the waterbody is commonly successfully assumed in numerical modeling. The aim of this studies was to analyze transport of chlorine inside the rural water supply system. The calculations were performed with application of Epanet 2.0 with assumed the first-order re action of chlorine decay and empirically determined chlorine decay rate in the mass of waterbody. The periodical disinfection of water in the network with the constant chlorine concentration $0.3 \mathrm{mg} \cdot \mathrm{dm}^{-3}$ introduced during the whole time duration of simulation was assumed to calculations. The obtained results of chlorine distribution showed that even after 4 days there were available pipelines in which concentration of free chlorine was lower than $0.2 \mathrm{mg} \cdot \mathrm{dm}^{-3}$. Thus, the microbiological protection of water quality is unavailable in these pipelines.
\end{abstract}

\section{Introduction}

Concentration of free chlorine in water is one of the most important factors directly affecting the quality of water delivered to consumers. Doses of chlorine used in practice are result of the required need of assuring the microbiological protection of water during transport to the customers as well as limiting development of by-products of disinfection (DBPs) threatening the humans health [1-5]. According to guidelines by WHO, the concentration of free chlorine in sampling points should be in range $0.2-0.5 \mathrm{mg} \cdot \mathrm{dm}^{-3}[6]$

Two parallel reactions occur in the process of chlorine decay. One in the boundary layer, the second in mass of waterbody. According to the complexity and numerous factors affecting ratio of these reactions, modeling of chlorine transport in water distribution systems requires the separate determination of values of chlorine decay constants. The total chlorine decay constant $(k)(1)$ is commonly expressed as sum of constant of chlorine decay

* Corresponding author: a.musz-pomorska@pollub.pl 
in mass of water $\left(k_{b}\right)$ (dependent to the initial characteristics of water: temperature, initial chlorine concentration and content of organic components) [7-9] and constant of chlorine decay in the boundary layer $\left(k_{w}\right)$ (related to pipe diameter, velocity of flow and pipe material) [10].

$$
k=k_{b}+k_{w}
$$

The constant of chlorine decay in mass of water is commonly determined empirically in numerical modeling $[11,12]$ while the constant of chlorine decay in the boundary layer is obtained by the trial and errors method during calibration of qualitative model [13]. The $k_{w}$ constant is less frequently determined empirically [14].

Nowadays, several models allowing simulations of water quality inside the water supply systems are available [15-17]. One of the most popular is Epanet 2.0 [18], allowing calculations of chlorine transport, studies of increase in DBPs and trihalomethanes concentrations as well as determination of water age [19].The kinetics of chlorine decay in Epanet 2.0 is described by the first-order reaction (2), in relation to which, the final concentration is dependent only to the initial concentration of one component. In case of chlorine transport, its final concentration is related only to its initial concentration.

$$
c=c_{0} e^{-k t}
$$

where: $c$ - chlorine concentration in time $t\left[\mathrm{mg} \cdot \mathrm{dm}^{-3}\right], c_{0}$ - initial chlorine concentration $\left[\mathrm{mg} \cdot \mathrm{dm}^{-3}\right], k$ - constant of chlorine decay rate $\left[\mathrm{min}^{-1}\right], t-$ time $[\mathrm{min}]$.

The studies reported by Ozdemir and Ucak (2002) [20] based on comparison of modeling results obtained in Epanet and DYNAQ to results of measurements of chlorine concentration in nodes of water supply system showed satisfactory agreement between results of calculations and measurements.

The aim of this paper was to analyze chlorine transport in rural water supply system. Our studies were performed in Epanet 2.0 modeling software with applied hydraulic model of the tested network. The first-order reaction of chlorine decay and empirically determined value of constant of chlorine decay in water mass were assumed to our calculations. The periodical disinfection of water in the network with the constant chlorine concentration $0.3 \mathrm{mg} \cdot \mathrm{dm}^{-3}$ introduced during the whole time duration of simulation was assumed to calculations.

\section{Materials and methods}

Numerical calculations of chlorine transport inside the water distribution network were performed in Epanet 2.0 computational software, distributed by EPA, US. (United States Environmental Protection Agency), with the applied hydraulic model of the tested system. The applied hydraulic model was earlier calibrated in relation to measured pressure and values of volumetric flow rate of water inside the pipelines. The studied network had annularbranched structure and was supplied with water by single water supply station. The network consisted of polyvinyl chloride (PVC) pipes of total length equal to $16.4 \mathrm{~km}$. Diameters of pipes were in range $80-200 \mathrm{~mm}$, but the greatest share had pipelines of diameter $150 \mathrm{~mm}-$ approx. $37 \%$, while the lowest part was represented by pipes of $200 \mathrm{~mm}-0.9 \%$.

\subsection{Hydraulic model}

The developed hydraulic model representing, in a simplified manner, the studied water supply network, consisted of 200 nodes, 203 lines and one reservoir. The computational water demands in 
the developed model were based on readouts of domestic watermeters while hourly water demand pattern was based on readouts of the main watermeter located in the water supply station (Fig. 1).

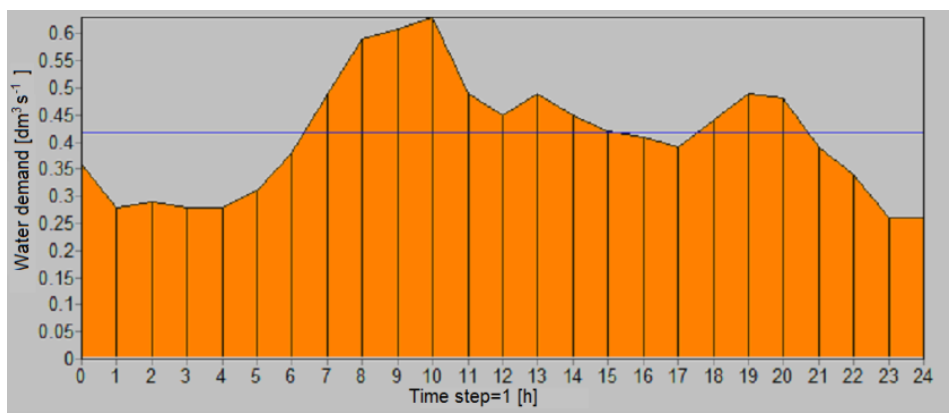

Fig. 1. Water demand pattern.

The determined value of unit water demand for an individual water supply network user was equal $0.012 \mathrm{dm}^{3} \cdot \mathrm{s}^{-1}$. The value of pipe material roughness was assumed as $0.02 \mathrm{~mm}$ for all of the modeled pipelines [21]. Pressure at the exit of water supply station was sustained at the level of approx. $35 \mathrm{~m} \mathrm{H}_{2} \mathrm{O}$. Volumetric flow rates of water during hours of minimal and maximal water demand inside the main water supply pipeline were equal $4.77 \mathrm{dm}^{3} \cdot \mathrm{s}^{-1}$ and $1.97 \mathrm{dm}^{3} \cdot \mathrm{s}^{-1}$, respectively.

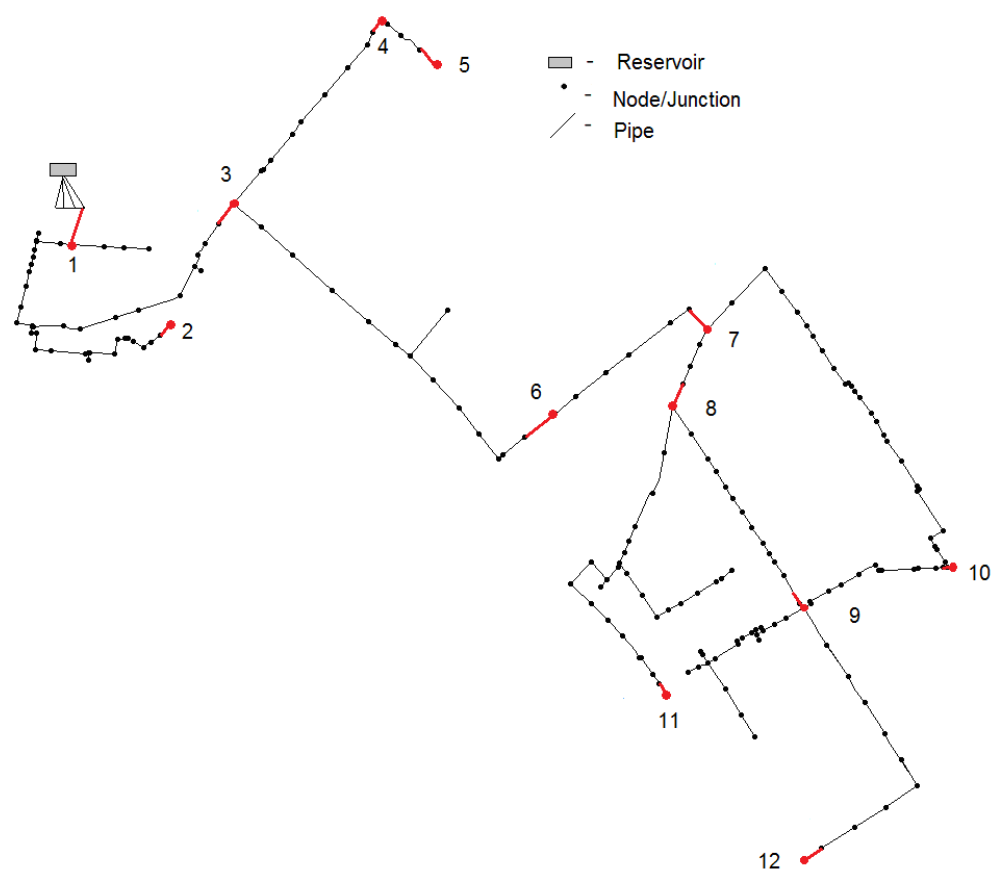

Fig. 2. Network scheme with marked characteristic nodes and pipelines.

In order to determine the chlorine distribution inside the tested water supply network 12 characteristic nodes and 12 pipelines were selected (Fig. 2). The choice was determined by the distance to pumping station, value of daily changes in values of hydraulic parameters and required coverage of the whole network. Description of the selected nodes and pipelines as well as their labels in the model are presented in Table 1. 
Table 1. Description of the characteristic nodes and pipes.

\begin{tabular}{|c|c|c|c|c|c|c|c|c|c|c|c|c|}
\hline Description & $\mathbf{1}$ & $\mathbf{2}$ & $\mathbf{3}$ & $\mathbf{4}$ & $\mathbf{5}$ & $\mathbf{6}$ & $\mathbf{7}$ & $\mathbf{8}$ & $\mathbf{9}$ & $\mathbf{1 0}$ & $\mathbf{1 1}$ & $\mathbf{1 2}$ \\
\hline Nodes & w2 & J9 & w128 & J3 & J1 & w18 & w149 & w151 & w157 & W85 & J53 & J69 \\
\hline Pipelines & R2 & R45 & R10 & R64 & R17 & R190 & R 80 & R142 & R178 & R105 & R159 & R185 \\
\hline
\end{tabular}

\subsection{Quality model}

Numerical calculations of chlorine transport inside pipelines of the studied network were based on the first-order model of chlorine decay, according to equation (2) [14, 22, 23] with value of constant of chlorine decay rate in the boundary layer of the pipeline accepted after literature as $k_{w}=0.04 \mathrm{~h}^{-1}[7,8]$ and empirically determined constant of chlorine decay in the mass of water $k_{b}$. The chlorine concentration equal $0.3 \mathrm{mg} \cdot \mathrm{dm}^{-3}$ was assumed at the output of the pumping station. Dosing of chlorine was assumed as constant during the whole time duration of simulation -4 days $(96 \mathrm{hr})$. Time duration of water chlorination process was assumed basing directly on information obtained from the local water supply company. Taking into account that water in the studied network is being chlorinated periodically after failures or servicing, the initial concentration of chlorine $\left(\mathrm{c}_{0}\right)$ was assumed in our research as $0 \mathrm{mg} \cdot \mathrm{dm}^{-3}$. The assumed time duration for determination of water age was accepted as equal to time of water chlorination in the network. This time duration is in accordance with so called "long" time of water retention inside the pipelines, according to literature data, greater than 3 days [24].

\subsubsection{Determination of the chlorine decay rate in water body}

The constant of chlorine decay rate in mass of water $k_{b}$ was determined with application of the bottle test described by Vieira et al. (2004) [12] on the laboratory set-up presented in Fig. 3.

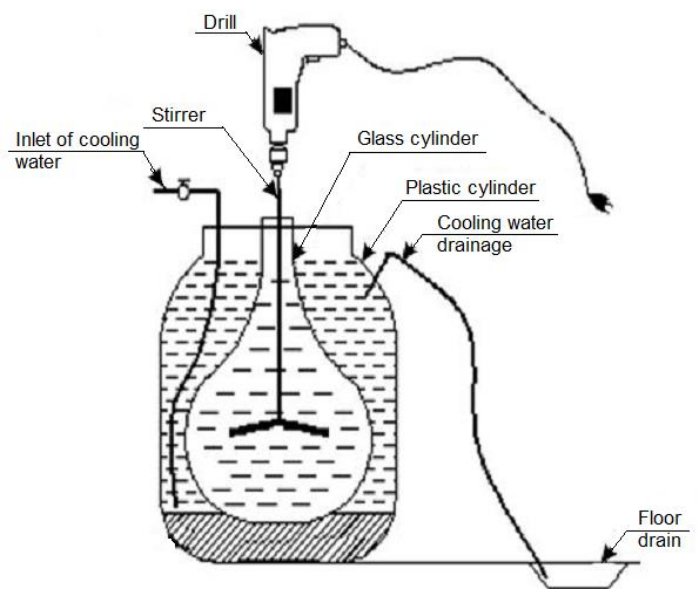

Fig. 3. Laboratory set-up for $k_{b}$ determination.

Water for the research was sampled in water supply station and immediately transported to the laboratory. Then, the glass balloon of $54 \mathrm{dm}^{3}$ (Fig. 3) was filled with the tested water. Next, sodium hypochlorite containing $200 \mathrm{mg} \cdot \mathrm{dm}^{-3}$ of the active chlorine was added to water. Temperature of water inside the glass reservoir was sustained at the level of approx. $16^{\circ} \mathrm{C}$. After exhaustive mixing of water with stirrer, samples were taken according to the assumed 
schedule. The chlorine content in the obtained samples was determined with PC Mulit Direct meter using the colorimetric method DPD, according to PN-EN ISO 7393-2:2011 [25].

\section{Results}

The results of laboratory changes of chlorine concentration in water sampled from the tested water distribution network are presented in Figs. 4 and 5. The obtained results show a very quick consumption of chlorine during the opening phase of the experiment (the first 3 hours of measurements) (Fig.4). During this phase the initial concentration of free chlorine decreased by $0.4 \mathrm{mg} \cdot \mathrm{dm}^{-3}$ (from $2.24 \mathrm{mg} \cdot \mathrm{dm}^{-3}$ to $1.84 \mathrm{mg} \cdot \mathrm{dm}^{-3}$ ). During the second phase, from $3^{\text {rd }}$ to $24^{\text {th }}$ hour of the experiment the significantly slower decrease in free chlorine concentration was observed, from $1.84 \mathrm{mg} \cdot \mathrm{dm}^{-3}$ to $1.40 \mathrm{mg} \cdot \mathrm{dm}^{-3}$. The observed dynamics of decrease in chlorine concentration is being supported by previously reported results by Vieira et al. (2004) [12]. The constant of chlorine decay in mass of water was determined basing on the observed changes in chlorine concentration and the assumed first-order equation of chlorine decay. In case of the first-order decay the $k_{b}$ constant is determined as tangent of inclination angle of the straight line obtained by the natural logarithm of $c_{t} / c_{0}$ in time $t$ [18] (Fig.5). The determined value of constant $k_{b}$ was equal $0.0182 \mathrm{~h}^{-1}$.

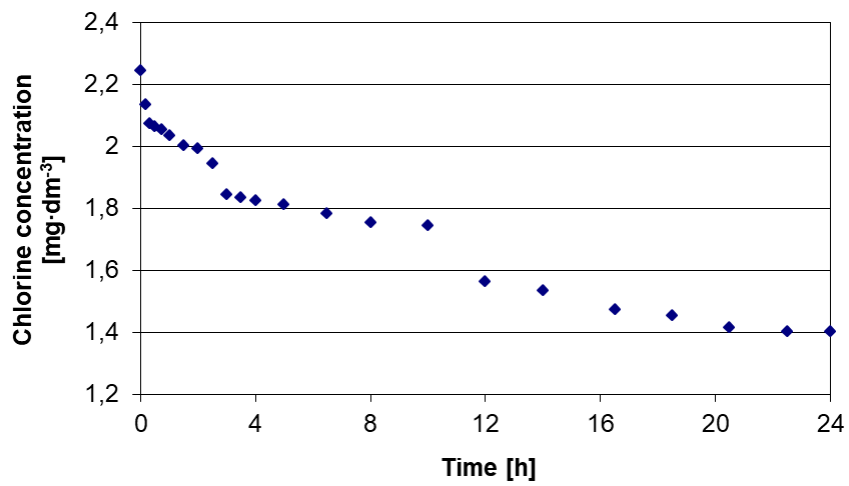

Fig. 4. Chlorine concentration in water during laboratory measurements.

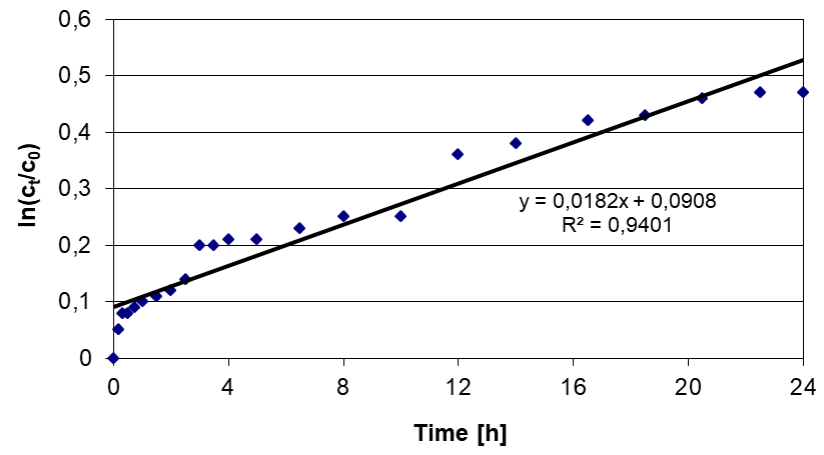

Fig. 5. Changes of chlorine concentration in water.

The calculated numerical results of chlorine transport obtained for the selected nodes are presented in Table 2. Table 3 presents computed results covering selected 
characteristics of flow in the chosen pipelines obtained for the $96^{\text {th }}$ hour of the assumed time duration of simulation.

The performed numerical calculations showed low values of water flow velocity inside the modeled pipelines (from $0.06 \mathrm{~m} \cdot \mathrm{s}^{-1}$ to $0.15 \mathrm{~m} \cdot \mathrm{s}^{-1}$ in the pipeline supplying the studied network). The required value of velocity equal $0.5 \mathrm{~m} \cdot \mathrm{s}^{-1}$ was not achieved in none of the pipelines [26], which may negatively affect the qualitative characteristics of water and may result in deposition of sediments inside the pipelines and increase in roughness as well as development of bio-film [27]. The maximum water demand $\left(q=4.77 \mathrm{dm}^{3} \cdot \mathrm{s}^{-1}\right)$ was observed at 10.00 while the minimal at $23.00\left(q=1.97 \mathrm{dm}^{3} \cdot \mathrm{s}^{-1}\right)$.

Table 2. Chlorine concentration on selected nodes of the network.

\begin{tabular}{|c|c|c|c|c|c|c|c|c|c|c|c|c|}
\hline $\begin{array}{l}\text { Time } \\
\text { [hour] }\end{array}$ \\
\cline { 2 - 15 } \\
$\begin{array}{c}\text { Number } \\
\text { of node }\end{array}$ & $\mathbf{1}$ & $\mathbf{2}$ & $\mathbf{3}$ & $\mathbf{4}$ & $\mathbf{5}$ & $\mathbf{6}$ & $\mathbf{7}$ & $\mathbf{8}$ & $\mathbf{9}$ & $\mathbf{1 0}$ & $\mathbf{1 1}$ & $\mathbf{1 2}$ \\
\hline $\mathbf{1 2}$ & 0.30 & 0.00 & 0.25 & 0.00 & 0.00 & 0.00 & 0.00 & 0.00 & 0.00 & 0.00 & 0.00 & 0.00 \\
\hline $\mathbf{2 4}$ & 0.30 & 0.16 & 0.24 & 0.00 & 0.00 & 0.18 & 0.16 & 0.15 & 0.00 & 0.00 & 0.00 & 0.00 \\
\hline $\mathbf{4 8}$ & 0.30 & 0.16 & 0.24 & 0.17 & 0.00 & 0.18 & 0.16 & 0.15 & 0.02 & 0.07 & 0.00 & 0.00 \\
\hline $\mathbf{7 2}$ & 0.30 & 0.16 & 0.24 & 0.17 & 0.12 & 0.18 & 0.16 & 0.15 & 0.02 & 0.07 & 0.00 & 0.03 \\
\hline $\mathbf{9 6}$ & 0.30 & 0.16 & 0.24 & 0.17 & 0.12 & 0.18 & 0.16 & 0.15 & 0.02 & 0.07 & 0.04 & 0.04 \\
\hline
\end{tabular}

*Grey cells - chlorine concentration higher than $0.2 \mathrm{mg} \cdot \mathrm{dm}^{-3}$, minimal concentration required by WHO for drinking water

Table 3. Parameters of flow in selected pipes at 96 hours of modeling.

\begin{tabular}{|c|c|c|c|c|c|c|c|c|c|c|c|c|c|}
\hline \multirow{2}{*}{ Parameter } & \multirow{2}{*}{ Unit } & \multicolumn{10}{|c|}{ Number of pipe } \\
\cline { 3 - 14 } & & $\mathbf{1}$ & $\mathbf{2}$ & $\mathbf{3}$ & $\mathbf{4}$ & $\mathbf{5}$ & $\mathbf{6}$ & $\mathbf{7}$ & $\mathbf{8}$ & $\mathbf{9}$ & $\mathbf{1 0}$ & $\mathbf{1 1}$ & $\mathbf{1 2}$ \\
\hline Diameter & {$[\mathrm{mm}]$} & 200 & 80 & 150 & 80 & 100 & 150 & 150 & 100 & 100 & 80 & 80 & 80 \\
\hline Flow & {$\left[\mathrm{dm}^{3} \cdot \mathrm{s}^{-1}\right]$} & 2.73 & 0.03 & 1.30 & 0.09 & 0.05 & 1.05 & 0.97 & 0.52 & 0.19 & 0.25 & 0.00 & 0.03 \\
\hline Velocity & {$\left[\mathrm{m}^{-1} \mathrm{~s}^{-1}\right.$} & 0.09 & 0.01 & 0.07 & 0.01 & 0.01 & 0.06 & 0.06 & 0.07 & 0.02 & 0.03 & 0.00 & 0.01 \\
\hline Age & {$[\mathrm{h}]$} & 1.64 & 15.8 & 5.6 & 41.4 & 53.1 & 12.6 & 15.4 & 16.4 & 26.6 & 32.0 & 81.0 & 65.3 \\
\hline
\end{tabular}

Figure 6 presents scheme of isolines of chlorine concentration in water and age of water inside the pipelines.

a)

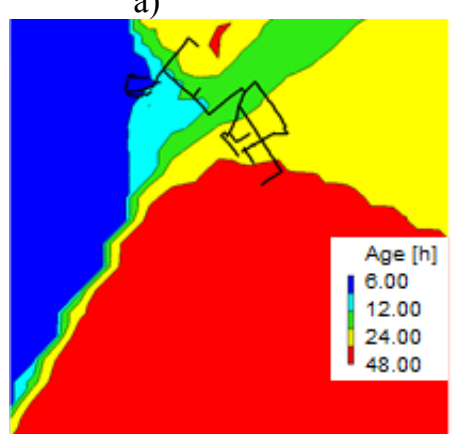

b)

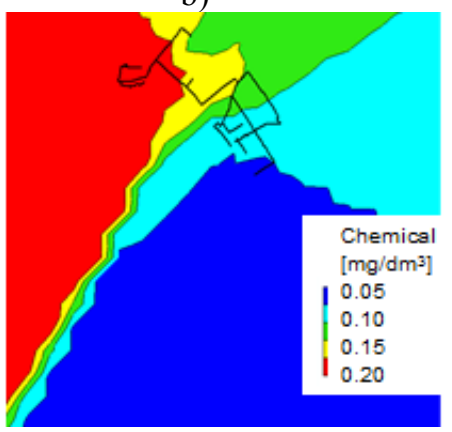

Fig. 6. Scheme of counter lines dividing: a) the water age in pipelines, b) chlorine concentration in water.

The obtained computational results of chlorine transport inside the studied rural water supply system show that the periodical chlorination of water in the network with the assumed dose of disinfectant through the selected time does not assure the required minimal 
concentration of free chlorine (according to WHO recommendations, minimum $\left.0.2 \mathrm{mg} \mathrm{Cl}_{2} \cdot \mathrm{dm}^{-3}\right)$. Simultaneously, the acceptable concentration of chlorine in water $\left(0.3 \mathrm{mg} \cdot \mathrm{dm}^{-3}\right)$ was not exceeded in any node of the network [28]. The highest chlorine concentration was observed in nodes close to the water supply station (nodes 1 and 3), located on the main conduit supplying the whole water distribution system (Fig. 6).

The modeled disinfectant reaches the final nodes in the network with the significant delay since the start of chlorination process (Table 2). Pipelines supplying water to final nodes of the network are characterized by very low values of volumetric flow rate and velocity of flow as well as very long age of water in the pipelines (Table 3 ). The age of water in pipeline supplying water to node No 11 exceeds 3 days. Figure 5 shows that the shortest water age (less than $6 \mathrm{~h}$ ) was observed in pipelines close to water supply station, while the longest in the final parts of the system. The significant water age, accompanied by lack of the required concentration of disinfectant may result in development of microorganisms, deposition of sediments and deterioration of water quality [29].

\section{Conclusions}

Availability of computer simulation models allows analysis of qualitative characteristics inside water supply systems, including chlorine transport. The quality of obtained results depends on the assumed input data, selection of the proper model of disinfectant transport or determined values of constants of disinfectant decay rate. Our calculations of chlorine transport in rural water distribution system, performed in Epanet 2.0 with assumption of first-order equation of chlorine decay and determined empirically constant of chlorine decay rate exposed very low concentrations of free chlorine in modeled tap water, below $0.2 \mathrm{mg} \cdot \mathrm{dm}^{-3}$, which combined with low values of flow velocities and extended water age do not assure the microbiological protection of water quality. In relation to periodic disinfection of water inside the studied supply network, measurements of chlorine concentration in selected points of system were unavailable and indisposed calibration of developed qualitative model. Taking into account lack of qualitative model calibration, the obtained results should be treated as preliminary and approximate. However, they pose an important information about operation conditions of the tested network. In future, the developed qualitative model should be calibrated basing on measured values of free chlorine concentrations in the selected nodes of the studied system. The presented study will be also extended to allow the selection of the proper chlorine dose due to results of numerical studies of the influence of various doses of disinfectant on water quality in the network.

\section{References}

1. Y. Zhao, Y. J. Yang, Y. Shao, J. Neal, T. Zhang, Water Res. 141, 32-45 (2018)

2. R. V. Goyal, H. M. Patel, Appl. Water Sci. 5, 311-319 (2015)

3. D. L. Boccelli, M. E. Tryby, J. G. Uber, R. S. Summers, Water Res. 37, 2654-2666 (2003)

4. Y. Bixiong, W. Wuyi, Y. Linsheng, W. Jianrong, E. Xueli, J. Hazard. Mater. 171, 1-3, 147-152 (2009)

5. Z. K. Chowdhury, L. Passantino, R. S. Summers, L. Work, N. Smith, L. Rossman, Assessment of Chloramine and Chlorine Residual Decay in the Distribution System (AWWA Research Foundation, Denver, Colorado, 2006)

6. WHO Guidelines for drinking water quality, $4^{\text {th }}$ ed., (WHO, Geneva, 2011) 
7. J. C. Powell, N. B. Hallam, J. R.West, C. F. Forster, J. Simms, Water Res. 34, 1, 117-126 (2000)

8. R. M. Clark, R. C. Haught, J. Water Res. Plan. Man. 131, 3, 208-217 (2005)

9. F. Shang, G. Uber, J. Water Res. Plan. Man., ASCE 133, 4, 363-371 (2007)

10. N. B. Hallamn, J. R.West, C. F. Forster, J. C. Powell, I. Spencer, Water Res. 36, 3479-3488 (2002)

11. L. Monteiro, D. Figueiredo, S. Dias, R. Freitas, D. Covas, J. Menaia, Proc Eng. 70, 1192-1200 (2014)

12. P. Vieira, S. T. Coelho, D. Loureiro, J. of Water Supply Res. T. - AQUA, 53, 7, 453-467 (2004)

13. S. H. Maier, R. S. Powell, C. A. Woodward, Water Resour. Res. 34, 8, 2301-2309 (2000)

14. A. O. Al-Jasser, Water Res. 41, 387-396 (2007)

15. I. E. Karadirek, S. Soyupak, H. Muhammetoglu, Desalin. Water Treat. 57, 25, 11592-11598 (2016)

16. A. G. Seyoum, T. T. Tanyimboh, C. Siew, Water Sci. Tech.-W. Sup. 13, 4, 1161-1166 (2013)

17. A. Musz, B. Kowalska, M. K. Widomski, Ecol. Chem. Engineer. S, 16, 2, 175-184 (2009)

18. L. A. Rossman, EPANET 2 Users Manual. Water Supply and Water Resources Division, National Risk Management Research Laboratory, Office of Research and Development (US Environmental Protection Agency, Cincinnati, Ohio, 2000)

19. F. Shang, J. G. Uber, L. A. Rossman, J. Environ. Sci. Technol. 42, 3, 808-814 (2008)

20. O. N. Ozdemir, A. Ucak, J. Environ. Eng. ASCE, 128, 1, 31-39 (2002)

21. W. W. Sharp, T. M. Walski, J. Am. Water Works. Ass. 80, 11, (1988)

22. B. Kowalska, D. Kowalski, A. Musz, Environ. Prot. Eng. 32, 2, 5-16 (2006)

23. H. Kim, S. Kim, J. Koo, Procedia Eng. 119, 370-378 (2015)

24. S. Shu, S. Liu, X. Wang, L. Yu, S. Shu, D. Zhang, International Conference on MACE. 1918-1921 (2010)

25. PN-EN ISO 7393-2 Water quality - Determination of free chlorine and general chlorine - Part 2: Colorimetric method with N, N-diethyl-1,4-phenylenediamine, for routine control purposes (2011)

26. M. Kwietniewski, W. Olszewski, E. Osuch-Pajdzińska, Projektowanie elementów systemu zaopatrzenia w wodę (Oficyna Wydawnicza Politechniki Warszawskiej, Warszawa, 2009)

27. D. Kowalski, M. Kwietniewski, A. Musz, M. K.Widomski, Ochr Środ. 30, 1, 27-30 (2008)

28. Rozporządzenie Ministra Zdrowia z 2015 r. w sprawie jakości wody przeznaczonej do spożycia przez ludzi (Dz.U. 2015, poz. 1989)

29. S. C. Tinker, C. L. Moe, M. Klein, W. D. Flanders, J. Uber, A. Amirtharajah, J. Water Health. 7, 2, 332-343 (2009) 